\title{
Sequential Voting Models with Externalities
}

\author{
Xiaoqin Huang \\ College of Computer and Information Science \\ Southwest University, \\ Chongqing, China \\ e-mail: xiaoqinhuang_swu@126.com \\ Yiming He \\ College of Computer and Information Science \\ Southwest University \\ Chongqing, China \\ e-mail: \\ georgehym@qq.vip.com
}

\author{
Liang Li \\ College of Computer and Information Science \\ Southwest University \\ Chongqing, China \\ e-mail: liliangswu@163.com \\ Guoliang Liu \\ College of Computer and Information Science \\ Southwest University \\ Chongqing, China \\ e-mail: \\ 404149074@qq.com
}

\author{
Wu Chen (corresponding author) \\ College of Computer and Information Science \\ Southwest University \\ Chongqing, China \\ e-mail: \\ chenwu@swu.edu.cn
}

\begin{abstract}
Voting is one of the important ways to solve the problem of collective decision-making. Previous work assumes that voters are only concerned about their own preference. However, in sequential voting, voters can see the results of voters who voted before them, such externalities naturally arise in sequential voting. This paper considers the externalities in sequential voting which use the traditional Borda counting rules. We establish a voting model to describe the voting strategies of sequential voting with externalities. In our prediction model, an agent will do a prediction in the case that he cannot bring change to the voting result no matter how he changes his preference order, under this circumstance, an agent will vote in accordance with his preference order. The voting model provides a theoretical reference for the actual situation of voting behavior.
\end{abstract}

Keywords-component; Externalities; Strategy Voting; Sequential Voting; Borda rule; Prediction

\section{INTRODUCTION}

Voting is a very common phenomenon in our daily life. Voting rules and voting systems have been widespread concerned and become one of the focuses in collective decision-making. The study of formally defined voting systems is called social choice theory or voting theory, which is a subfield of political science, economics, or mathematics. Different voting systems use different types of voting rules. Common voting rules are Borda, Nanson, Baldwin methods and so on.

One of the common classifications of voting are sequential voting and simultaneous voting. In sequential voting, each voter observes the votes who vote before him. In simultaneous voting, each voter does not observe any others' votes before casting his votes. In the sequential voting, there may exist mutual influence among voters, which is called externalities in voting [1].General speaking, externalities are cost or benefits that are not transmitted through price, and may be incurred by a party that was not involved in a transaction. For example, in fair division between multiple agents, each agent may derive value not only from its own piece [2]. Unlike in traditional voting without externalities, voters not only need to consider their own preference sequences, but also need to consider other people's voting sequences. Theories of externalities are widely studied in economics [3-5], and recently have also been received attention widely in computer science literature, which includes coalitional games [6], matchings[7], fair divisions[8].

In voting, a stream of recent papers study the externalities, of which Alon takes the external effects into account among voters[1], he studied the sequential voting in the situation of two candidates, whose model aims to capture voting behavior ("likes") sequentialin social networks which are publicly observed and sequential[9]. Different from Alon, this paper establishes a voting model and a prediction model to analyze the process of sequential voting strategically. And our prediction model provides a theoretical reference to the actual situation of voting behavior.

\section{BORDA RULE}

Borda rule is a scoring system of the voting rules designed by Jean-Charles in 1770[10]. Each voter has a 
preference order of $m$ candidates, the score which candidates got is determined by their positions in the preference order of voters. When all voters finish their voting, the candidate who gains the highest score is the winner. The Borda rule is widely used in politics, sports and non-governmental organizations around the world (e.g. Slovenia's parliamentary elections, American University American football and all kinds of competitions.). One of the features of Borda count is that it considers not only the first choice but also other choices and the preferences of voters.

Example 1: There are 4 candidates and 9 voters, and the set $\{\mathrm{A}, \mathrm{B}, \mathrm{C}, \mathrm{D}\}$ represents the 4 candidates. The preference sequence of the voter $\mathrm{i}$ is expressed as $R_{i}$ ( $\mathrm{i}$ from 1 to 9 ), which are expressed as follow: $R_{1}$ : $C>D>A>B, R_{2}$ : $\mathrm{C}>\mathrm{D}>\mathrm{A}>\mathrm{B}, \mathrm{R}_{3}: \mathrm{D}>\mathrm{B}>\mathrm{A}>\mathrm{C}, \mathrm{R}_{4}: \mathrm{D}>\mathrm{B}>\mathrm{A}>\mathrm{C}, \mathrm{R}_{5}: \mathrm{B}>\mathrm{C}>\mathrm{A}>\mathrm{D}$, $\mathrm{R}_{6}: \quad \mathrm{B}>\mathrm{C}>\mathrm{A}>\mathrm{D}, \quad \mathrm{R}_{7}: \quad \mathrm{A}>\mathrm{B}>\mathrm{C}>\mathrm{D}, \quad \mathrm{R}_{8}: \quad \mathrm{A}>\mathrm{B}>\mathrm{C}>\mathrm{D}, \quad \mathrm{R}_{9}$ : $\mathrm{A}>\mathrm{B}>\mathrm{C}>\mathrm{D}$

If we note the first preference of the sequence 4 points, the second preference of the sequence 3 points, the third 2 points, and the last 1 point. That is to say, the election vector is $(4,3,2,1)$. According to the rules. The scores of 4 candidates are:

$$
\begin{aligned}
& \text { Score }(A)=2 * 6+4 * 3=24 \\
& \text { Score }(B)=1 * 2+3 * 5+4 * 2=25 \\
& \text { Score }(C)=4 * 2+1 * 2+3 * 2+2 * 3=22 \\
& \text { Score }(D)=3 * 2+4 * 2+1 * 5=19 \\
& \text { The winner of the voting is B. }
\end{aligned}
$$

But if we change the election vector $(4,3,2,1)$, which may change the voting results. such as in the Nauru parliamentary elections they ranked the first preference of the sequence to get 1 point, ranked the second on the $1 / 2=$ 0.50 points, ranked the third at $1 / 3=0.33$ points, and the last preference was ranked to get $1 / 4=0.25$ points, which means that the election vector is $(1,1 / 2,1 / 3,1 / 4)$, According to the rules, the resulting scores of 4 candidates are as follow:

Score $(A)=0.33 * 6+1 * 3=4.98$

Score $(\mathrm{B})=0.25 * 2+0.5 * 5+1 * 2=5$

Score $(C)=1 * 2+0.25 * 2+0.5 * 2+0.33 * 3=4.49$

Score $(\mathrm{D})=0.5 * 2+1 * 2+0.25 * 5=5.5$

The winner of this vote is D. In a word, a different election vector will lead to a different election results.

What's more, a different election vector will lead to a different election results.

\section{Voting Model And PREdiction Model}

We introduce a general model for voting with externalities, which including a set $\mathrm{S}$ of $\mathrm{m}$ voters and a set $A=\left\{a_{1}, a_{2}, a_{3}, \ldots, a_{n}\right\}$ of $n$ candidates. For voter $\mathrm{i}$, he have a preference sequence $\mathrm{Ri}$, which represents his preference for $\mathrm{n}$ candidates (in which $a_{p} \succ a_{q}\left(a_{p}, a_{q} \in A\right)$ means that voter i prefers $a_{p}$ to $\left.a_{q}(1<\mathrm{p}, \mathrm{q}<\mathrm{n})\right)$. In order to express the preference degree of candidates for voter $\mathrm{i}, \operatorname{rank}\left(a_{q}, R_{i}\right)$ is used to represent the position of $a_{q}$ in $R_{i} . a_{b e s t}$ is the favorite candidate, that is to say, $a_{b e s t}$ is at the first position of the preference sequence. The candidate $a_{f}$ is the current winner who is at the first position of the voting results. $R_{i}^{T}$ is used to represent the voting sequence of voter $i$. Each candidate will gain a score $V_{i}\left(a_{q}\right),(q=1,2,3, \ldots, n)$ after voter $\mathrm{i}$ finishing voting. $V_{i}^{P}\left(a_{q}\right)$ is used to represent the strategic voting score of voter $i$ to candidate $a_{q}(q=1,2,3, \ldots, n)$.

For voting rule, it is a mapping from the set of all preference profiles to the set of candidates, voters assign scores to each candidates through voting rule, in which the selection vector $\Pi=(\mathrm{n}, \mathrm{n}-1, \quad \ldots, \quad 2,1)$ plays an important role[1]. After all the voters finishing voting, candidate $a_{q}$ will get the final score $\operatorname{score}\left(a_{q}\right)=V_{n}\left(a_{q}\right)$.The winner is the candidate who gain the highest score.

Example2:There are 4 voters, $\mathrm{S}=\{$ Pol, Hrey, Jok, Cin $\}$, and 4 alternatives, $\mathrm{A}=\left\{a_{1}, a_{2}, a_{3}, a_{4}\right\}$, For each voter, his preferences can be seen in Table 1 :

TABLE I. THE PREFERENCE OF VOTERS

\begin{tabular}{|l|l|}
\hline voters & preference \\
\hline Pol & $a_{1} \succ a_{2} \succ a_{3} \succ a_{4}$ \\
\hline Hery & $a_{2} \succ a_{3} \succ a_{4} \succ a_{1}$ \\
\hline Jok & $a_{3} \succ a_{4} \succ a_{2} \succ a_{1}$ \\
\hline Cin & $a_{4} \succ a_{3} \succ a_{2} \succ a_{1}$ \\
\hline
\end{tabular}

Voters vote in sequence. The election vector $\Pi=$ $(4,3,2,1)$.According to the voting rules, voters adjust their vote according to the results of the voters before. After the four voters finishing, we can see that the winner is $a_{4}$. In contrast, the winner of the voting according to the traditional Borda rule is $a_{3}$. Obviously, the consideration of externalities in voting with Borda rules contributes a big difference to the voting results.

\section{A. Voting Model}

How voters behave in sequential voting with externalities? In this model, this paper assumes that voters do not know the preferences of other voters, and they cannot communicate with each other during the voting. Also we assume that voters are natural person, and they all hope that their first preferred candidate becomes the winner

Consider the externalities for voter $i$ and candidate $a_{p}$. When it is the voter's turn to vote, he will vote on the basis of the score of the prior voter $V_{i-1}\left(a_{p}\right)$ and the score of $a_{p}$ in his preference order, and then work out a new 
score $V_{i}\left(a_{p}\right)$. At last, voter i finishes his voting according to the score. We can see the relationship between $V_{i}\left(a_{b e s t}\right)$ and $V_{i}\left(a_{p}\right)$ in figure 1 , and the process of strategy is as follows: $a_{p}$ is any other candidates.

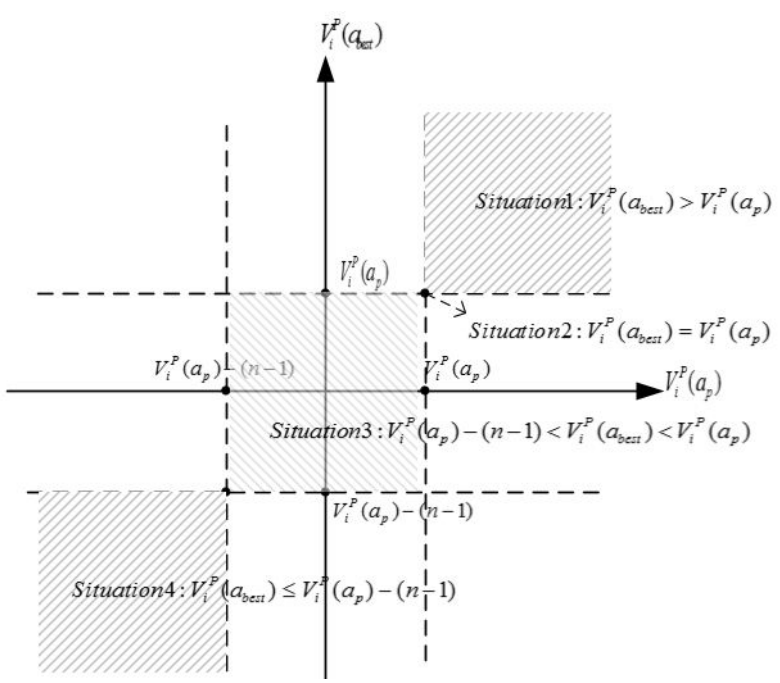

Figure 1. The relationship between $V_{i}\left(a_{\text {best }}\right)$ and $V_{i}\left(a_{p}\right)$

- $\quad$ For voter i, if $V_{\mathrm{i}}^{P}\left(a_{\text {best }}\right)>V_{i}^{P}\left(a_{p}\right)$, his voting sequence will be $R_{i}^{T}=R_{i}$, the winner of this round is $a_{\text {best }}$, who is his favorite candidates.

- If there exist $a_{p}$ s.t. $V_{\mathrm{i}}^{P}\left(a_{\text {best }}\right)=V_{i}^{P}\left(a_{p}\right)$, in order to make $a_{\text {best }}$ become winner, let $\operatorname{rank}\left(a_{p}, R_{i}^{T}\right)=4, \operatorname{rank}\left(a_{\text {best }}, R_{i}^{T}\right)=1$ and the other candidates are ordered as the preference sequence. After his voting, the winner of this round is $a_{\text {best }}$.

- If there exist $a_{p}, \quad$ s.t. $V_{i}^{P}\left(a_{p}\right)>V_{i}^{P}\left(a_{b e s t}\right)>V_{i}^{P}\left(a_{p}\right)-(n-1)$, the dealing will be same as Situation 2. After his voting, the winner of this round is $a_{\text {best }}$.

- If there exist $a_{p}, \quad$ s.t. $V_{\mathrm{i}}^{P}\left(a_{\text {best }}\right) \leq V_{i}^{P}\left(a_{p}\right)-(n-1) \quad$ under this circumstances, even if set $\operatorname{rank}\left(a_{p}, R_{i}^{T}\right)=4, \operatorname{rank}\left(a_{\text {best }}, R_{i}^{T}\right)=1, a_{\text {best }}$ cannot beat $a_{f}$ (the current winner) to become the new winner, most can be a tie as possible: $V_{i}\left(a_{\text {best }}\right)=V_{i}\left(a_{p}\right)$. The result of this voting will depend on the voting later, and now, voter $\mathrm{i}$ will make a prediction to the voting later, after which he will decide his voting sequence $R_{i}^{T}$.

In a word, $V_{\mathrm{i}}^{P}\left(a_{\text {best }}\right) \leq V_{i}^{P}\left(a_{p}\right)-(n-1)$ is the point that voters will have a prediction to the voting later.

Example 3: The known condition is as example 2. In accordance with the voting rules described in this paper, Voters will vote in sequence. For the first voter Pol, it is no doubt that he will vote as his preference: $a_{1} \succ a_{2} \succ a_{3} \succ a_{4}$. After his voting, others can see the voting result score $V_{1}\left(a_{q}\right)(\mathrm{q}=1,2,3,4)$ (Table 2$)$.

TABLE II. ThE VOtING RESUlt SCORE $V_{1}\left(a_{q}\right)$

\begin{tabular}{|c|c|}
\hline$V_{1}\left(a_{q}\right)$ & Score \\
\hline$V_{1}\left(a_{1}\right)$ & 4 \\
\hline$V_{1}\left(a_{2}\right)$ & 3 \\
\hline$V_{1}\left(a_{3}\right)$ & 2 \\
\hline$V_{1}\left(a_{4}\right)$ & 1 \\
\hline
\end{tabular}

After the first voting, the second voter may vote for his preference candidates with some changes to his preference. Voter 2 has a preference of $a_{2} \succ a_{3} \succ a_{4} \succ a_{1}$. He will assume voting according to his own preferences, then work out evaluation scores $V_{2}^{\mathrm{P}}\left(a_{q}\right)(\mathrm{q}=1,2,3,4)$ for each candidate (Table 3):

TABLE III. The EVALUATION SCORE $V_{2}^{P}\left(a_{q}\right)$

\begin{tabular}{|c|c|}
\hline$V_{2}^{P}\left(a_{q}\right)$ & Score \\
\hline$V_{2}^{P}\left(a_{1}\right)$ & 5 \\
\hline$V_{2}^{P}\left(a_{2}\right)$ & 7 \\
\hline$V_{2}^{P}\left(a_{3}\right)$ & 5 \\
\hline$V_{2}^{P}\left(a_{4}\right)$ & 3 \\
\hline
\end{tabular}

evaluation scores $V_{2}\left(a_{q}\right)=V_{2}^{P}\left(a_{q}\right)(\mathrm{q}=1,2,3,4)$. In the third voting, the third voter work out evaluation scores $V_{3}^{\mathrm{P}}\left(a_{q}\right),(\mathrm{q}=1,2,3,4)$ for each candidate as $(6,9,9,6)$.Just like it in situation 2 , the adjusted plan is to let $\operatorname{rank}\left(a_{2}, R_{3}^{T}\right)=4$ and $\operatorname{rank}\left(a_{3}, R_{3}^{T}\right)=1$. Then $a_{2}$ beat $a_{3}$ to becoming the winner of this round. According to the same rules, voter 4 will change his adjusted plan to let the voting sequence $R_{4}^{T}=a_{4} \succ a_{2} \succ a_{1} \succ a_{3}$ After 4 voters finishing voting, the winner is $a_{4}$. 


\section{B. Prediction Model}

As we can see from example 3, even though the first preference $a_{b e s t}$ has been adjusted to the first position, and the current winner $a_{f}$ has been adjusted to the last position. It is impossible to make $a_{\text {best }}$ beating $a_{f}$. Just like in situation 4, for voter $\mathrm{i}$, if there exists $a_{p}$, s.t. $V_{\mathrm{i}}^{P}\left(a_{\text {best }}\right) \leq V_{i}^{P}\left(a_{p}\right)-(n-1) \quad\left(a_{p}\right.$ is any other candidates), no matter how he adjust his voting sequence $R_{i}^{T}$, he cannot change the winner $a_{p}$ to $a_{b e s t}$ (or exist the case of tie score). On this occasion, voters will make predictions for the voting later. In the Prediction, known that the number of voters that complete voting is $\mathrm{F}$, and the number of all the voters is $\mathrm{M}$. (M-F>0)

- If there exists $a_{f}, a_{q}$, s.t. $V_{\mathrm{i}}^{P}\left(a_{f}\right)-V_{i}^{P}\left(a_{q}\right)>(n-1)(M-F)$ (in which $a_{f}$ is the winner of the prior voting, and $a_{q}$ is the candidate who gain the second highest score ), that is to say, the winner is far ahead, and it is no double that $a_{f}$ is the winner of this voting.

Specially, just like the Situation 4-1, if ${ }^{a_{q}}$ happens to be the first preference of voter $i$. That is to say, there exists $a_{f}$, s.t. $V_{\mathrm{i}}^{P}\left(a_{f}\right)-V_{i}^{P}\left(a_{\text {best }}\right)>(n-1)(M-F)$. We can see $a_{\text {best }}$ will not be the winner. Now what should voter i do is that taking the second preference as the first. Then, voters $i$ will give up his first preference, and take the second preference into reconsideration as the first, and repeat above steps in accordance with the rules, and determine the voting sequence.

- If $V_{\mathrm{i}}^{P}\left(a_{f}\right)-V_{i}^{P}\left(a_{\text {best }}\right) \leq(n-1)(M-F) \quad$ (in which $a_{f}$ is the winner of the prior voting), voters voting later may have a chance to change the voting results, to make $a_{\text {best }}$ beat $a_{f}$ to be the winner. All voter $\mathrm{i}$ can do is to make $\operatorname{rank}\left(a_{q}, R_{i}^{T}\right)=4$ and $\operatorname{rank}\left(a_{b e s t}, R_{i}^{T}\right)=1$.In this way, voter $\mathrm{i}$ tries his best to help his first preference $a_{\text {best }}$ to become the winner, next step is to persuade voters to vote for $a_{b e s t}$.

\section{CONCLUSION}

Our paper pays attention to the externalities in sequential voting, and takes the sequential voting with Borda rules as an example, analyzes the process of voting with strategies. One of the important contributions of this paper is establishing voting models and prediction models with concrete example. We draw a conclusion that the point of the voter to do a prediction is no matter how he adjust his voting sequence, his first preference cannot beat the current winner to become the winner of this round. All these studies provide a theoretical reference for the actual situation of voting behavior. Moreover, the future work in this field we plan to do is the voting strategy among intelligence agents.

\section{ACKNOWLEDGEMENT}

The research work was supported by "the Fundamental Research Funds for the Central Universities" (XDJK2014C040)

\section{REFERENCES}

[1] Noga Alon, Moshe Babaioff, Ron Karidi, Ron Lavi, and Moshe Tennenholtz. "Sequential Voting with Externalities: Herding in Social Networks". In Proceedings of ACM EC. 2012.

[2] Branzei, Simina, Ariel Procaccia, and Jie Zhang. "Externalities in Cake Cutting." International Joint Conference on Artificial Intelligence. 2013.

[3] Katz, Michael L., and Carl Shapiro. "Technology adoption in the presence of network externalities." The journal of political economy : pp.822-841. 1986.

[4] Ayres, Robert U., and Allen V. Kneese. "Production, consumption, and externalities." The American Economic Review: pp. 282-297. 1969.

[5] Katz, Michael L., and Carl Shapiro. "Network externalities, competition, and compatibility." The American economic review: pp.424-440. 1985

[6] Michalak, Tomasz P., et al. "On representing coalitional games with externalities." Proceedings of the 10th ACM conference on Electronic commerce. ACM, 2009.

[7] Brânzei, Simina, et al. "Matchings with externalities and attitudes."Proceedings of the 2013 international conference on Autonomous agents and multi-agent systems. International Foundation for Autonomous Agents and Multiagent Systems. 2013.

[8] Miltersen, Peter B. "Equilibrium Analysis in Cake Cutting." In Proceedings of the 12th International Joint Conference on Autonomous Agents and Multi-Agent Systems (AAMAS), Forthcoming. 2013.

[9] Dekel, Eddie, and Michele Piccione. "Sequential voting procedures in symmetric binary elections." Journal of Political Economy 108.1 : pp.34-55. 2000.

[10] Young, H. Peyton. "An axiomatization of Borda's rule." Journal of Economic Theory 9.1 : pp.43-52. 1974 